\title{
Occurrence of Botrytis Crown Rot Caused by Botrytis cinerea in Lettuce in Southern New Mexico
}

\author{
Soum Sanogo, ${ }^{1,+}$ Srijana Dura, ${ }^{1}$ Phillip Lujan, ${ }^{2}$ Jesus Barraza, ${ }^{1}$ and Balkissa Kapran ${ }^{1}$ \\ ${ }^{1}$ Department of Entomology, Plant Pathology, and Weed Science, New Mexico State University, Las Cruces, NM 88003 \\ ${ }^{2}$ Department of Extension Plant Science, New Mexico State University, Las Cruces, NM 88003
}

Accepted for publication 25 April 2019.

Keywords: crown rot, vegetables, Botrytis cinerea, Lactuca sativa

Lettuce (Lactuca sativa L.) is a high-value crop in the United States and worldwide. In 2017, production of lettuce in the United States was valued over $\$ 4$ billion (USDA-NASS 2018), with California as the leading producing state. In New Mexico, lettuce is a minor crop, and yearly production information is not provided in the agricultural statistics bulletin of the state. The 2012 census of agriculture for New Mexico indicated that lettuce was produced only in Doña Ana County in southern New Mexico on 93 farms, and 543 acres were harvested (USDA-NASS 2018). In Doña Ana County, lettuce is grown as a rotational crop to other vegetable crops such as chile and onion. Disease pressure is typically nil in lettuce fields.

On November 26, 2018, a 10-ha field of unharvested lettuce west of Las Cruces, New Mexico, was visited during a field trip organized as part of a course on diagnosing plant disorders at New Mexico State University. About $60 \%$ of the field was planted to iceberg lettuce (cultivar information was unavailable) and $40 \%$ to romaine lettuce (cultivar Sunbelt). The field site and surrounding area experienced a hail event (Fig. 1A), which caused more physical damage to the iceberg lettuce (Fig. 1B) than the romaine lettuce (Fig. 1C). The hail event took place 10 days before the harvesting was scheduled to take place. Owing to the damage incurred from the hail, the field was not harvested. During the scouting of the field, romaine lettuce plants were found wilted, and some collapsed onto the soil surface in the planting bed (Fig. 2). The crowns of severely affected plants were rotted and were easily pulled. Grayish mycelium mats covered with spore masses were found at the crown of infected plants (Fig. 2). On several pulled crowns, black sclerotia were found. Incidence of the disease was less than $1 \%$, and the diseased plants were scattered as single plants throughout the field. No plant wilting or plant collapse were observed in the iceberg lettuce.

Microscopic observations of the grayish mycelium mats and spores revealed a conidial apparatus that was macronematous, with clusters of oblong conidia borne on branched conidiophores.

${ }^{\dagger}$ Corresponding author: S. Sanogo; E-mail: ssanogo@ad.nmsu.edu

Funding: This work was funded by the Agricultural Experiment Station, New Mexico State University.

The author(s) declare no conflict of interest.

(C) 2019 The American Phytopathological Society
Based on the microscopic observations and the field symptoms as described by Bohn (1953), the mycelial microorganism found on diseased plants was identified as Botrytis cinerea. Pure cultures were established from infected tissues, sclerotia, and spore masses. Infected leaves displaying necrotic lesions at the base were washed in $0.5 \%$ Tergitol, dipped in sodium hypochlorite for $30 \mathrm{~s}$, and rinsed in sterile distilled water, and $0.5-\mathrm{cm}$ segments were cut off from the advancing edge of necrotic lesions and plated onto acidified potato dextrose agar medium. Emerging fungal colonies were transferred to potato dextrose agar medium to establish pure cultures. Molecular characterization of a representative culture was conducted by polymerase chain reaction amplification of the internal transcribed spacer region of rDNA using ITS1/ITS4 primers of the genomic DNA. Sequencing and BLAST analysis revealed a $99 \%$ homology with a sequence from $B$. cinerea (accession number MH997910.1, with over 458 bp of aligned sequence). The sample DNA sequence data were deposited to NCBI GenBank with accession number MK262920.1.

Asymptomatic romaine lettuce plants were uprooted from the same field and transplanted into $500-\mathrm{cm}^{3}$ Styrofoam cups. Plants were inoculated with two 1-cm-diameter mycelium plugs taken from a 5- to 7-day-old culture obtained from infected tissue (mycelial isolate) or from plated sclerotia (sclerotial isolate). A plug was inserted into the axil of a leaf selected on two diametrically opposite sides of the crown. Plants were misted with sterile distilled water and covered with a clear plastic bag, which was secured in place at the base of the plant with a rubber band for 1 week. Plants were maintained in a growth chamber with a temperature regime of $28^{\circ} \mathrm{C}$ day and $22^{\circ} \mathrm{C}$ night and a photoperiod of $14 \mathrm{~h}$. Four plants were inoculated with each isolate, with a plant serving as an experimental unit. Two noninoculated plants served as control. The experiment was conducted twice. All plants inoculated with each isolate (two isolates were used as indicated above) displayed lesions within 5 to 7 days (Fig. 3). Leaves on infected plants collapsed at the crown, as similarly observed on affected plants under field conditions. Reisolations from infected plants yielded cultures identical to those originally obtained from diseased plants collected in the field. To our knowledge, this study provides the first account of the occurrence of Botrytis crown rot in New Mexico. Cool temperatures in conjunction with rain and hail may have favored the onset of this disease. However, the extent of the disease is not known. Further surveys are warranted to ascertain the prevalence and incidence of Botrytis crown rot in the state. 

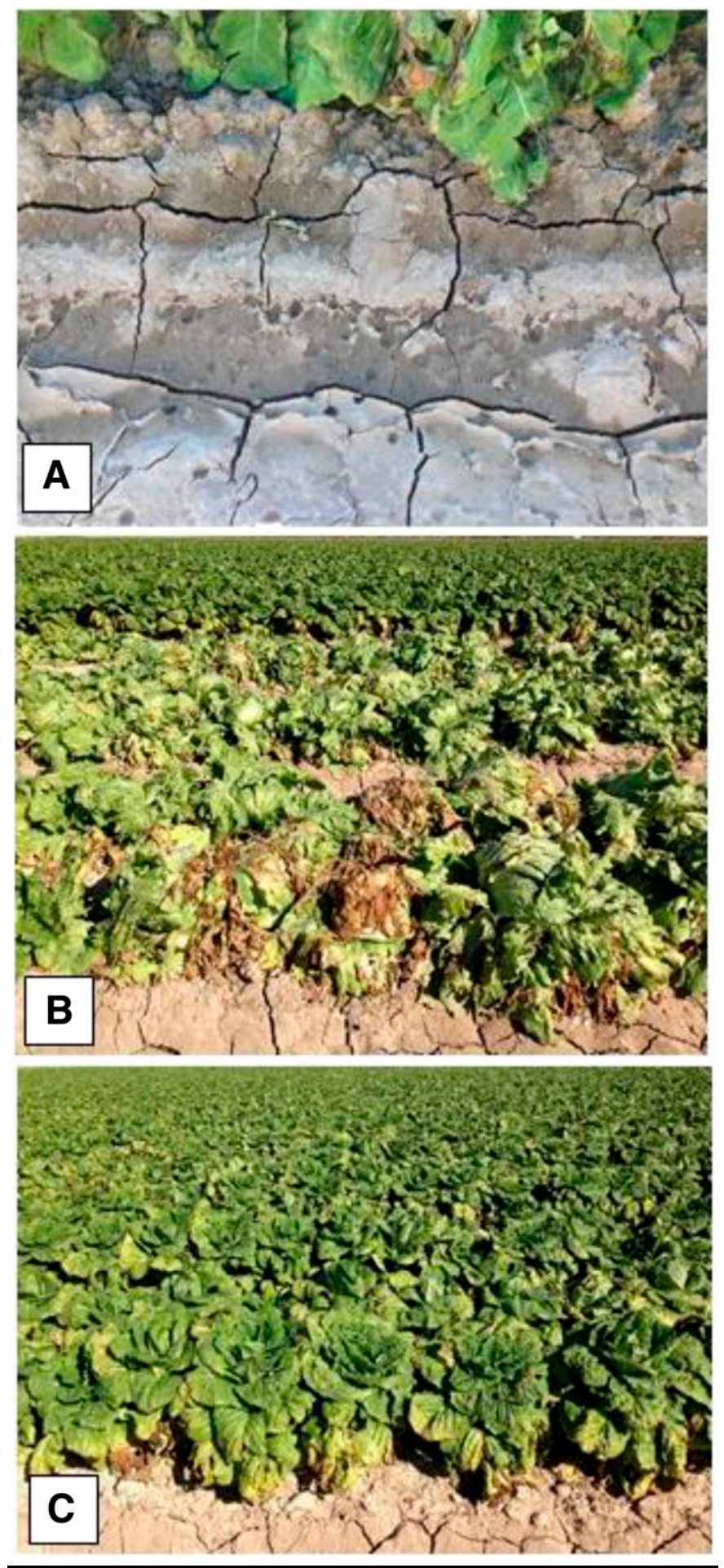

FIGURE 1

Impact of hail on lettuce: A, hail imprints on the surface of field soil; B, hail damage on iceberg lettuce; and $\mathbf{C}$, hail damage on romaine lettuce.

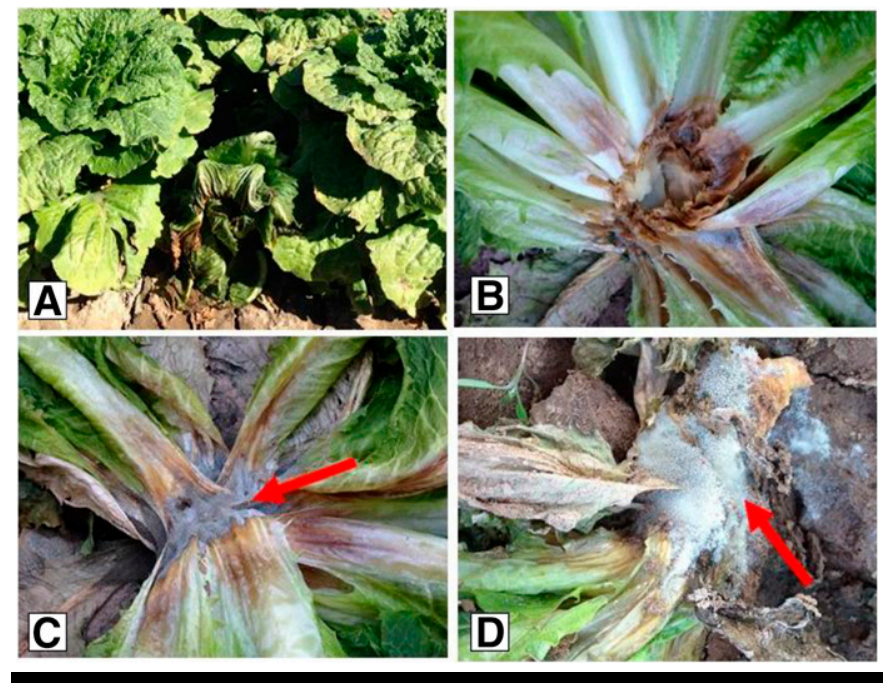

FIGURE 2

Lettuce plants displaying symptoms and signs of infection by Botrytis cinerea: A, plant affected by Botrytis crown rot in the midst of apparently healthy plants; B, crown of infected lettuce showing leaves with basal necrosis; C, diseased crown with spore masses (red arrow); and $\mathbf{D}$, mycelial mat and spore masses on an infected plant and soil (red arrow).

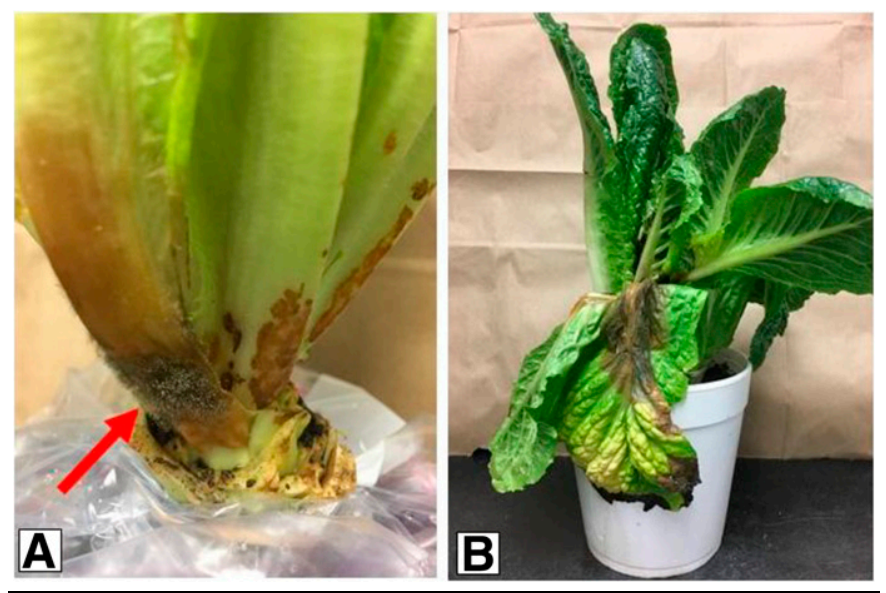

FIGURE 3

Pathogenicity of Botrytis cinerea on lettuce plants: A, lesion on the base of leaves displaying spore masses (red arrow); and $\mathbf{B}$, expanded lesion on an inoculated leaf.

\section{Literature Cited}

Bohn, G. W. 1953. The important diseases of lettuce. Pages 417-425 in: Yearbook of Agriculture. A. Stefferud, ed. U.S. Department of Agriculture, Washington, D.C.

USDA-NASS. 2018. Quick Stats, 2017. U.S. Department of Agriculture, National Agricultural Statistics Service, Washington, D.C. 